\title{
A Study of Refusal Speech Act in Chinese Dating Programs Take "If You Are The One" As an Example
}

\author{
Yiwen Wang \\ College of Chinese Language and Culture, Jinan University \\ Shougouling Road No.377 Tianhe District, Guangzhou, Guangdong, China \\ E-mail: 1203716444@qq.com
}

Doi:10.7575/aiac.alls.v.6n.3p.197

Received: $17 / 02 / 2014$

URL: http://dx.doi.org/10.7575/aiac.alls.v.6n.3p.197

Accepted: 24/04/2015

\begin{abstract}
Looking at the development of China dating programs, "If You Are The One" in Jiang Su satellite TV is the heated program drawing much attention from the public. There are some papers focusing on the dialogue in the program from the perspective of linguistic features or pragmatic function, but there are few papers on the refusal speech act in such programs. Based on the classified oral language data in the program, this paper studies the refusal speech act when male or female guest was asked to build a love relationship with someone. Under the guidance of the face theory (Brown \& Levinson), Politeness principle (Leech), we analysize the pragmatical difference of different refusal speech act. In addition, from the perspective of gender difference the study analyzes different refusal speech act patterns conducted by male and female guests in dating program and we find that men behave generally more direct while women are more euphemistic and polite in refusal speech act.
\end{abstract}

Keywords: Refusal Speech Act, Direct and indirect, Politeness principle, Gender differences, "If You Are The One"

\section{Introduction}

"If You Are The One" is a large dating program built by Jiangsu satellite TV to adapt to the pace of modern urban life, according to the similar program mode "Take Me Out" in Australian. There are 5 male guests coming for dating with 24 women who decide to accept the men or not with lights on or off. From the beginning, The program is loved by the majority of the people at home and abroad because of its elaborate production, continuous innovation mode and characteristic humor. "If You Are The One" has caused the discussion of the outlook on life, values and the view of the world. At the same time, a large number of scholars have studied this kind of program seen from the CNKI net, but most of such papers are based on the perspective of the news media, television art, social and economic aspects, such as Yin (2010), Li (2011), Liu (2013). There are also many researches carried out from feminism, social status, like Wang (2010), Zhao (2011). However, there are few reseaches carried out from the perspective of language. Based on discourse analysis and pragmatics, Hou (2011) compared and analyzed topics, turns, hosting styles, the principles of cooperation and other aspects in two programs "If You Are The One" and "Take Me Out". Yuan (2012) analyzed conversation between men and women in "If You Are The One" by means of evaluation theory, to find out the similarities and differences between the two in the negative attitude to the society, and probed into the causes of similarities and differences. Sun (2013) also studied program's conversational implicature by indirect politeness strategies, to help everyone understand the true meaning of guests and conversation. There are few papers from the perspective of indirect speech acts, but there are no any special researches about refusal speech act of such programmes and no studies appear professional system. Therefore, there is a big research space to our study on refusal speech act in Chinese dating programs.

\section{The research foundation}

\subsection{Refusal speech act}

Speech act theory is that language is a kind of behavior science. Linguistic study is a cross subject of behavioral science and social psychology and it includes both verbal forms and non-verbal forms, under the limit of pragmatic universal principle. The refusal speech act is a kind of verbal communication form where the speaker can make negative reaction to the recipient's request, invitation, suggestion, apology, greeting, compliment, instructions. The refusal speech act is a "non-cooperation" selection. In order to study, this paper defines it as the behavior of the speaker request speech act of refusal, mainly referring to the male and female guests request with get-together, the requested one don't agree. This kind of rejecting the existence of verbal expression and non verbal refuse refused in two different ways.

\section{2 the face theory and politeness principle}

Brown \& Levinson (1978) put forward the face theory on the relevant problems of politeness. The theory of the face is that every member of society to fight for their public self-image, is set by the actions of others to satisfy the desire, including positive face and negative face. People want to maintain face in the communicative activities, and with the increase of the degree of face threat, will use higher politeness strategies. In "If You Are The One", when guests 
refusing others' love request, often threat their "face", so the speaker who want to refuse often tries to make the face threats to a minimum as politely as possible, with multiple use of indirect speech acts as much as possible, implicitly expressed their feelings and ideas. In general, indirectness and politeness are related. The more indirect speech act of refusal, indicates a higher degree of politeness. But in the program, sometimes more direct refusal speech act are better, guests often used both of them.

\section{The analysis of refusal speech act}

\subsection{Data source}

In order to ensure the effective and scientific research, we random choose part of the program from October 12, 2013 to August 31, 2014 as the data source, and the relevant dialogue into text data, were collected and statistical data, and were classified and analyzed according to the need of study. Corpus content mainly is the refusal speech act that when guests refused to get-together, include speech and non-verbal refuse.

\subsection{Refusal speech act}

\subsubsection{Refusal speech}

Language is the main tool of communication between people, in the expression of rejected guests will generally use direct or indirect speech to ensure communication with complete. In this paper a refusal speech is classified into direct and indirect refusal refuse from the objective standard.

\subsubsection{Direct refusal}

Direct refusal generally use direct, concise and unreserved manner to achieve the speaker, by containing refused to central word sentence realization, or through the negation of will or their ability to express."If You Are The One" direct refusal does not see more, and most exist in the male guests' refusal, use the form of apology.

1)Meng Fei: Now number 10 left light on. That indicated that she is willing to go with you. If you are willing to, take her away from it; if not, say thanks when you leave.

Ge Lei: I have decided.

Meng Fei: What is your decision?

Ge Lei: Sorry.

2) Liu Quan: I'll go back to Beijing tomorrow. Who will follow me?

Anna: Sorry, I will still be here.

The above 2 cases are directly through the apology refuse, usually said "sorry", , sometimes with a body language.

3)Meng Fei: Last question.

Xue Panpan: Can u don't go to the club?

Zhang Kaxi: At present, I can't before I go ashore.

With the apology refuse is a polite way of refusing, impolite directly refuse also exists in "If You Are The One". The example occurred in female guest are willing to get-together with male guest, but the premise is that he doesn't go to the club again, The answer "no" is very direct and not polite.

\subsubsection{Indirect refusal}

Indirect refusal is way beyond the direct refusal, mainly based on pragmatic principles deduced the true intentions of those who refuse from discourse ${ }^{[11]}$, but most often will refuse indirect doping, such as "apology" and immediacy ingredients, have varied forms.

\subsection{Thanks to Refuse}

In the direction of his favour, regardless of whether or not success in hand, male and female guests normally expressed gratitude to the identity. Thanks to the approach is said to very gentle and polite, and programs need.

4)Meng Fei: Number 22 left light on. It indicated that she is willing to go with you. If you are willing to, take her away from it; if not, say thanks when you leave.

Qu Chao: Thanks for the girl, thank you!

5)Ma Kui: Thank you very very much for everything you just said, and your shining light.

Meng Fei: so?

Ma Kui: so I still choose No.5.

The refusal above is commonly used for indirect way, in that the other refused the request do not directly say no, but thanks. Sometimes in order to apologize, often said many times, such as Jolie refused to Ma kui vindicate explain many reasons, the last sentence is "thank you, thank you very much, thank you, thank you, thank you!".

\subsection{Explain self expectation to refuse}

Guests in "If You Are The One" have their own standards for finding lovers, only contact in a short time, few people will give up just because of moving or confession of self pursuit. Then tend to use "I want", "I think", "I want more" polite forms to explain the one who like him or her does not meet the requirement, refuse indirectly. 
6)Tang Huiling: Do you mind I am 11 years older than you? I am 41.

Lin Qiang: I still hope to find someone who is about the same age of me.

Tang Huiling: Wish you happy.

7) Fan Zhancheng: I will go to Shanghai tomorrow. Shall we go together?

Song Yini: This is my first time to stand here to be the Heartbeat girl. I am very grateful to you... I am a little woman. I hope to find a man who can lead me go forward. But I feel like you are not the one.

The examples to reveal their mate hopes and demands, like "I still hope to find someone about my age", "I hope to find a man to lead me go forward", when they said their own expectations of mate selection at the same time mean the other doesn't comply with the requirements, can't be accepted.

\subsection{Explain reasons to refuse}

For the need of cooperative principle and politeness principle in communication, guests tend to explain a lot of reasons to, especially women guests.

\section{8)(No.9 female guest shows her love with shining light)}

Li Shen: I pay much attention to the family and to be together. So thanks very much for No. 9 guests, then I hope to have the opportunity to communicate (with you). But as for No.10 guset, she is in Beijing and also in London. So she is very good for me.

9) Ye Wei: You're divorced. What a great ah ? I also have the experience of breaking up.

Wu Qiong: In fact, maybe there are still no feeling to you.

To explain the reasons for the refusal speech act is a kind of common way by women. This explaination including the geographical position, the gap and different between each other, feelings and self pursuit. Indirect refusal speech is often a variety of refusal strategies used, include main refusal language and auxiliary refusal language. The above example can be seen, Guests who want reject someone will generally express their gratitude, moved and recognition, and apologize to the one be rejected.

\subsection{Set out the issues to refuse}

The speech act of refusal will put some objective problems between men and women guests, such as distance, age, personality differences, let the other to quit, but also indirectly shows that the refusal is objectively required, to ease the embarrassment of each other.

10)Xu Bailin:... No.1 female guest have said that "fall in love at first sight". I believe and hope you can accept me.

Xu Nan: Male guests, first of all I am very grateful to you, then you are 24 years old this year, aren't you?

Xu Bailin: right, 24.

Xu Nan: Yeah, you know my age?

Xu Bailin: 29?

Xu Nan: Yeah... I think now you may not consider the age problem, but in later years, maybe you are aware of, after all, I am five years older than you. I feel for you, also a little unfair. You really very very good. But I'm sorry, you're too young for me (Bow).

When the male guest Xu Bailin insisted Heartbeat girl Xu Nan, she didn't directly rejected, but put them at five years of age difference, said it is not fair to him from the perspective of him. And said the male guest's excellent, but the age problem can not accept.

\subsection{Tell truth to refuse}

Refusal is not always refused to talk, some guests will take the move, enlighten them with reason in the way of tell truth. For example, female guest Guo Simin explain why refuse by analysis emotional consequences of get-together or not, compared to the two consequences, refuse is less harmful for the man.

11)Meng Fei: He said so long time for your love, do not have any words to respond?

Guo Simin: Thank you. Thank you for that you like me. This is me. But I did turn oft the light. I'm sorry. But if I go with you, I will sorry more because I don't love you.

3.2.1.2.6 Avoid the problem to refuse

Indirect refusal speech acts are not necessarily tactful, polite, some refuse may also be considered impolite, especially after refusing mood affected. In 12) after three short video of a foreign male guest Xiao $\mathrm{Lu}$, only one girl who he don't like with light on, which made him feel very frustrated. When host Meng Fei asked him if he wanted this girl, he avoided the problem, just said "I want to leave alone" indirectly expressed his unwilling,no thanks to the female guest, no bow to anyone.

12). Meng Fei: No.21 left light on. It indicated that she is willing to go with you. If you are willing to, take her away from it; if not, say thanks when you leave. What's your decision?

Xiao Lu: I want to leave alone.

\subsubsection{Non-verbal refuse}

Male and female guests not only use speech refuse, but also exist many non-verbal refuse expression. Samovar \& Mill points out, nonverbal communication covers all non speech stimuli in a certain communication situations, the stimulus 
is produced by the source and the environment, and have potential message value for the source or sink. Eye contact, facial expressions, body language and even silence is belong to nonverbal communication.

Nonverbal behavior in "If You Are The One" just have a small proportion, but also occurs. According to the special context of the program, this paper mainly discusses the silence and body language (Bow) which used in guests' refusal expression, and often used together. This nonverbal refusal is kind of indirect expression, but the content is often very directly, therefore, we will default to direct refuse.

13)(When a male guest is insisting that she is the heartbeat girl, Xu Nan uses a lot of direct and indirect denial. And yet, he repeatedly insists his request.)

Xu Nan: ......(90 degree bow three times)

When the words of refuse can not achieve the desired effect, $\mathrm{Xu}$ Nan properly remained silent and given three 90degree bow to male guest to convey refused apologize, but this way are rare in this stage.

\section{Gender differences in refuse mode}

Language is the production of society, under the influence of history and culture, social gender has specific expectations for the general male is usually considered manhood, mature, hard-working, and women should be kind, gentle, demure and understands courtesy. So this kind of social and cultural heritage in the psychological sense of gender in a long history. Men tends to speak more directly and active, while women are more euphemistic in communication ${ }^{[12]}$. When expressed refuse in "If You Are The One", male guests are often directly thanks or apology, but female guests prefer indirect refusal speech act, with a long list of thanks or explanations to show courtesy.

\subsection{Male guests' refusal mode: Thanks, Apology+Thanks}

People who familiar with the "If You Are The One " program knows that male guests refusing to female guests usually occurs in the final round that has only one female guest whom remain light on. At this time, Meng Fei will say now somebody leaving light, indicated that is willing to go with you, if you are willing, take her away from it, if not, say thanks when you leave. Make your decision clear and tell us." Because of the demand of the program, coupled with the direct determination of men, male guests in the refusal is usually use thanks, apology or a combination of the both. Such as generally simple "thank you" or "sorry for female guest", specific examples is below.

14)Meng Fei: No.18 left light on. It indicated that she is willing to go with you. If you are willing to, take her away from it; if not, say thanks when you leave. Make your decision clearly and tell us.

Han Wei (saying while walking) : Thank you.

15)Meng Fei: Explosion light girl Panpan, give you a bit of time finally.

Xue Panpan: Anyway. About the problem bounce, if you can solve it, pull, I'll go with you, If not, do what you like.

Zhang Xishun :Sorry, thank you.

From the above example can see, Male guests rejected directly and decisively through expressing gratitude and apology. According to incomplete study, the main refusal mode of male guests is "thanks" and "apology+thanks", often accompanying by physical action "bow". But some male guests will also use some explanation which be felt more polite.

\subsection{Female guests' refusal mode :Diversification}

Female guests refused to male guests' confession and love general occurs when a male guests came just for her or in the final round where the male guests is insists the heartbeat girl who don't love him. Because of women language is often indirect, pay attention to emotion and care about others, so female guests' refuse to overall more euphemistic and polite, the reject mode is diversified. Besides the same modes with he male guests, the female refusal also includes more euphemistic modes, such as "(thanks) + expression recognition + apology", "(thanks) + justification+apologize", "(thanks) + talk about the truth+apologize" and so on, a conversational turn often ends associated with ceremonial bow. For example:

\section{6) (Zheng Xiaoqing starts confessing his love to Zhu Wanlin)}

Zhuwan Lin: I wanna say you would probably think he is very good, but this is a blind date stage, not a arena about how to evaluate the character of a person. You are good, you are very excellent, but I stand here just to find a lover that evokes me to like him and want to release the desire of leave this arena with his hand. Indeed, I have to admit that you are very good, but I think I have no feeling to you and you can not hold me. I'm sorry, I'm sorry, so sorry.

\section{7) (Li Yakun specially starts confessing his love to Liu Taoling)}

Liu Taoling: Thank your sincerity, thank you for your intentions. But how to say, I personally feel, my feeling may be biased. I personally feel that you might be extremely a macho man. Of course, this is not necessarily right. In fact, maybe I like the kind of soft and gentle man......

The above example were used "(thanks) + expression recognition + apology" and "(thanks) + justification + apologize" refusal modes, this refusal expression is very polite, euphemism and indirect, it fits for the principle "the more indirect the more polite". There are many other example, not going to repeat them here. 


\section{Conclusion}

"If You Are The One" leads the development of TV dating shows in recent years. Its rich and unique language expression is becoming a research hotspot. Based on the theory of politeness principle especially face theory and the previous studies on refusal speech act we describe the refusal speech act that the guests used in the programs. Then we summarize the different refusal strategies used in the expression of male and female guests. Through the different perspectives of "verbal refusal" and "non-verbal refusal", we classify clearly the different speech act of refusal in "If You Are The One". The paper also summarizes the different refusal modes in directly and indirectly refusal and we find that men behave generally more direct while women are more euphemistic and polite in refusal speech act. By analysis of real oral corpus from "If You Are The One", our understanding of the speech act of refusal becomes more in-depth, and in a certain extent it enriches the research of the program in Linguistics.

\section{Reference}

Brown, P., \& Levinson, S. C. (1978). Universals in language usage: Politeness phenomena. Cambridge University Press.

Hou, Y. (2011). Language Features and Strategies of the TV Dating Show. Unpublished Master dissertation, Shanxi Normal University, 41.

Li, S. (2011). The Study of "If You Are The One" in Integrated Marketing Communication. Unpublished Master dissertation, Yunnan University.

Liu, L., Wan Q., \& Chen Z. (2013). Industry Economics Analysis about "If You Are The One". Dongyue Tribune, 34(5), 130-134.

Liu, Y. (2010). Politeness and Gender Differences in Language, Journal of Heilongjiang Vocational Institute of Ecological Engineering, 32(4), 148-149.

Sun, F. (2013). An Analysis of the Implicature in TV Program "If You Are The One" According to the Off-Record Strategy, Unpublished Master dissertation, Henan University.

Wang, X. (2010). Analysis of the Social Status of Chinese Women from "If You Are The One", Huazhang, $20,19$.

Yan, X. (2006). Refusals and Strategic Analysis, Master dissertation, Shanghai International Studies University, 1-2.

Yin, H. (2010). If You Are The One": Emotion in Entertainment. Modern Communication, 5, 81-82.

Yuan, C. (2012). An Analysis of Gender Language in TV Dating Show from the Perspective of Attituade System in Appraisal Theory--Take "If You Are The One" for example, Master dissertation, Jinan University, 1-2.

Zhao, J. (2011). The Construction of Femininities in TV Dating Programs--A Case Study of If You are the One by Jiangsu Satellite TV, Journal of China Women's University, 6, 54-59. 